\title{
Apparatus for the Photo-Electric Measurement of Submarine Illumination assembled for the U.S.A. Research Ship Atlantis.
}

\author{
By
}

D. C. Gall and W. R. G. Atkins.

With 4 Figures in the Text.

\section{INTRODUCTION.}

SHELFORD and Gail (1922) first used photo-electric cells for submarine photometry in the Puget Sound. Poole (1925) produced an apparatus which was suitable for use on small ships in the open sea. This apparatus was used near Plymouth by Poole and Atkins (1926, 1928, 1929) with various minor alterations in design which rendered it more reliable and less subject to errors due to electrical leakage. The object of these researches was to study illumination in relation to photosynthesis, but Russell perceived their bearing on his own work on the phototropic movements of the zooplankton. When considering the research programme of the Atlantis, Dr. George L. Clarke decided that it would be of value to carry out photo-electric measurements of submarine illuminations in connection with his work on vertical distribution of the plankton. A request was accordingly made by Dr. H. B. Bigelow, Director of the Wood's Hole Oceanographic Institute, that such an apparatus should be assembled under our direction. The apparatus here described has been constructed closely upon the lines of H. H. Poole's original apparatus as modified in 1928. Special attention, however, has been given to the elimination of electrical leakage. Furthermore, J. H. J. Poole (1928) devised an apparatus in which rate of flash of a neon lamp was used to measure light. This rate of flash method is one of integration and not an instantaneous measurement as is that of H. H. Poole. The value of the neon lamp method lies in the fact that light under the water is extremely variable near the surface owing to the motion of the waves. This method of measuring under-water illumination was used in Lough Bray, Co. Dublin, by J. H. J. and H. H. Poole (1930), and has since been used at sea by Poole and Atkins (1931): It seemed advisable to include a neon lamp photometer in the outfit so that errors in determining the loss of light on entering the water might be minimised. 


\section{The Potentiometer Apparatus.}

This equipment is a functional copy of that in use at Plymouth. The original apparatus had been assembled from various parts, and in reproducing this the opportunity was taken of making the constructional improvement possible in apparatus being designed for a specific purpose. One of the chief difficulties is that of insulation, because photo-electric measurements are essentially measurements of very high resistance. During sea fog, surface leakage becomes a serious matter, and in designing the present apparatus this was one of the principal problems to be overcome. The measuring apparatus shown in Figure 1 consists of a potentiometer with associated circuits to measure the current passing through the photo-electric cells under different degrees of illumination. The potentiometer has two dials, the main dial consisting of 18 steps of $0 \cdot 1$ volts, and the slide-wire subdivided into calibrated divisions of 0.001 volts, readable by estimation to 0.0001 volts. A reducing ratio extends the range to one-tenth of the above values, so that the total range of measurement covered is from 1.9 volts to 10 micro-volts. The current passing through the photo-electric cell is measured by observing the volt drop upon a standard resistance in series with it. This resistance consists of 10 steps of $10,000 \mathrm{ohms}$ each, giving a total of $100,000 \mathrm{ohms}$. With this combination photo-electric currents from $1.9 \times 10^{-4}$ down to $10^{-9}$ ampere can be measured. To prevent surface leakage at the potentiometer this instrument is totally enclosed in an air-tight metal box. The spindles operating the dials are brought out through glands of a type which has been found successful in somewhat similar instruments for field use. The terminals are all of a special " petticoat" type, hermetically sealed into the metal case with a special high insulating compound. The advantage of this petticoat type of terminal is that the surface leakage path, besides being very long, is shielded from light, and constructed so that condensation from the atmosphere cannot easily form upon the inside surface of the petticoat. The metal top of this instrument is sealed to the case with a rubber gasket between the two metal surfaces. A drying chamber containing calcium chloride is provided to remove the residual moisture inside the instrument. This same type of sealed construction is used for the 100,000 ohms subdivided standard resistance, by means of which the photo-electric currents are measured. A further advantage resulting from this form of metallic construction is that no direct leakage can take place between terminals should the insulation at any time be lowered, but must first leak to the metal case. This allows of employing a "guard" circuit to deflect such leakage away from the measuring circuit. To provide for this, each metal case is highly insulated from the metal lining to the sea-chest containing 


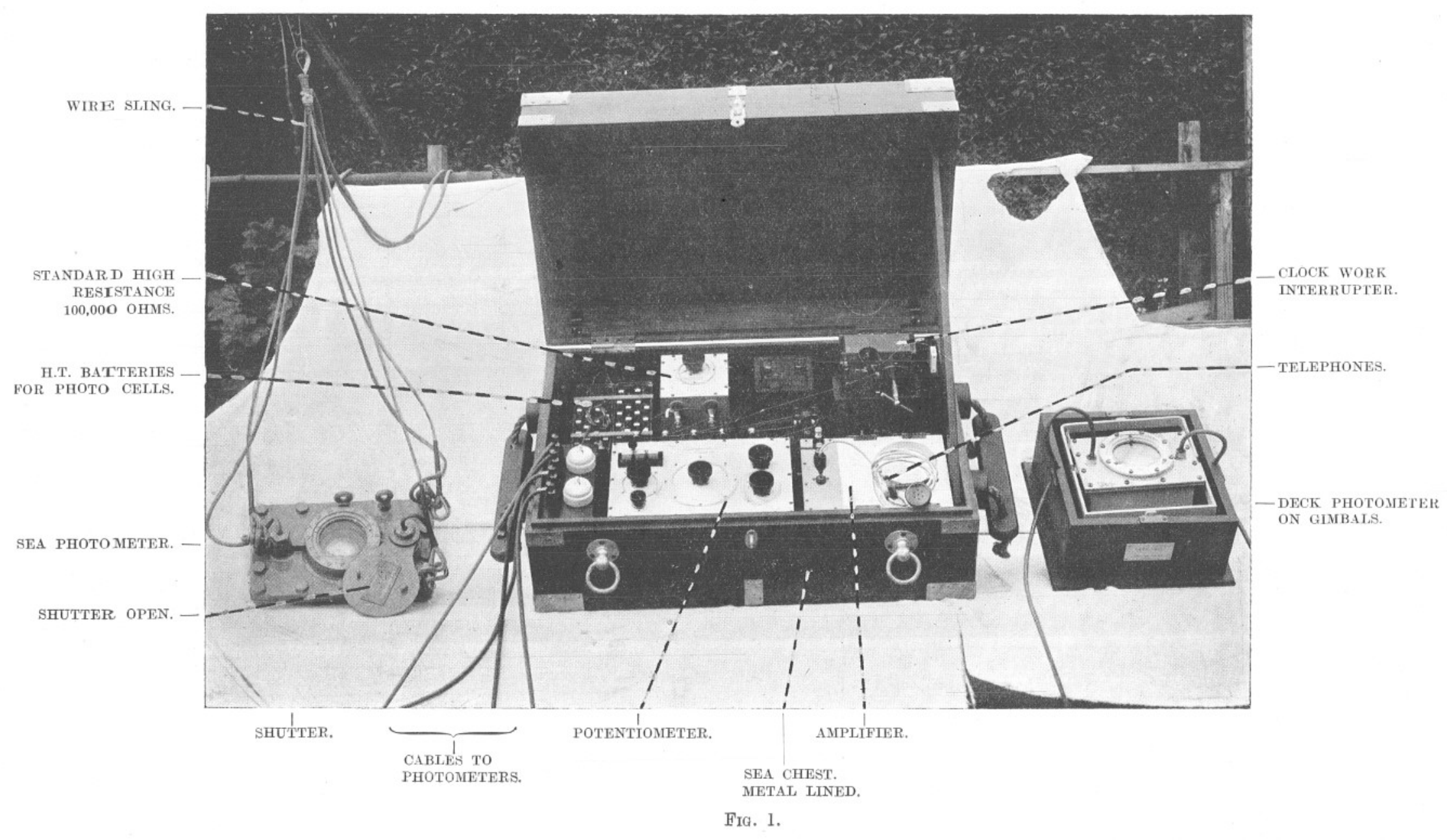



the complete potentiometer and accessories. The instruments have no direct connexion between their metal cases, but are all mounted upon the common metal lining, so that all leakage must be localised to this. By raising the potential of any one of the cases to an appropriate value, any tendency to leakage can be neutralised. When finally tested the insulation was so perfect that it was found unnecessary to make use of the guard circuit facilities, but during fog and other bad conditions need might arise and they would then be available. The insulation of the finished apparatus was tested in a steam-saturated chamber for half an hour without any observable effect upon the insulation.

The potentiometer sea-chest contains all the apparatus required for the measurements. This consists of the high-tension battery, potentiometer, high resistance, standards cells, accumulator for the potentiometer, clockwork interrupter, and valve amplifier and telephone which takes the place of a very sensitive galvonometer in this equipment. Electric heating of the chest is provided for drying out in bad weather. This is intended for use with the ship's electric supply current, 110 volts D.C.

In the original instrument the clockwork interrupter was made of "Meccano" parts at very small cost. Although this has given wonderfully reliable service it was felt that something better should be provided in a finished design. A Morse telegraph clockwork movement was chosen on account of the known reliability of these for continual service. The interrupter is constructed upon fundamentally the same principles as that described by Poole and Atkins (1928), and consists of a ratchettoothed wheel in rolling contact with a smooth jockey wheel. Mechanical refinements in adjustment for wear are introduced, and manganin is employed to reduce thermo-electric effects in the contact itself as these appear directly in the measuring circuit. Parasitic E.M.F.'s in the contact maker are further reduced by shunting a small condenser across the contact. The complete explanation of these parasitic E.M.F.'s is not fully clear, but they have been eliminated by these means. With the high amplification employed in the valve amplifier (about 30 decibels) any stray potential entering into the circuit becomes of importance. The clockwork drive is necessary because a motor is too liable to give stray electrical effects. The chief sources of these in the present instrument were found to be thermo-electric and frictional electrical effects in the mechanical contact maker and induction from external lighting and power circuits. The former were overcome by the use of manganin against brass, and the condenser as mentioned above, while the latter were completely eliminated by metal screening the whole circuit. This was rendered easy by the all-metal construction adopted for all the components of the circuit. A certain amount of experiment was 
necessary to find the best points at which to connect the screens, but the final results fully justify the precautions. A very perfect silence can be obtained in the telephones, and the photo-electric currents balance with ample precision. The amplifier has three stages and is operated by dry cells contained in its own metal case, so that no leakage paths are anywhere provided, and further, the screening is rendered complete. The telephone leads also are screened and arranged to be at "earth" potential, so that the balance is quite unaffected by the operator's body. This also guards against insulation troubles from this part of the circuit. The precaution has one drawback, in that it definitely fixes the potential of the operator, so that when the high-tension battery is accidentally touched the full 50 to 100 volts is felt. This causes some surprise to the unsuspecting, but is a necessary price to pay for perfection of balance.

\section{The Photo-electric Photometers.}

The deck photometer and the sea photometer, although considerably larger, are constructed upon lines identical with the originals at the Marine Biological Association Laboratory. The cells themselves were specially made by the General Electric Company at Wembley and are much larger than those in use at Plymouth. This necessitates much more massive construction for the gun-metal casting in which the sea cells are contained.

The general appearance of the deck and submarine photometers is shown in Figure 1. In the latter the photo-electric cell is supported resiliantly from the lid on highly insulating ebonite supports. The bottom casting is sealed to the lid with a rubber gasket between the two machined faces and clamped by massive bolts. The glass windows are $3.2 \mathrm{~cm}$. thick, and sealed between rubber washers by means of a clamping ring. A close-fitting sliding shutter closes this window when necessary to measure the "dark currents." This shutter is operated by cords from the surface, suitable fairleads being provided on the lid and wire cable upon which the submarine photometer is suspended. The two heavily rubbered cables to the terminals of the photo-electric cell enter the lid through glands, arranged to contract conical rubber stoppers on to the rubber covering of the cables. This type of joint has been found to be perfectly satisfactory. Drying chambers are provided inside the photometers to remove any residual moisture. When assembled, the insulation at the ends of the cables was more than a million megohms.

One submarine photometer is provided with cable sufficient for measurements down to 200 metres and the other for depths of 100 metres. Each is arranged for vertical suspension as well as horizontal. For vertical suspension the single wire cable shown in the extreme left of Figure 1 is 
undone and fixed through a shackle hole in a fin on the bottom of the case midway between the two shackle eyelet bolts on right of case.

In the case of the photometer for use down to 200 metres, the photo-electric cell is a gas-filled one, but for use down to 100 metres, and for the deck photometer, vacuum cells were used. All three were potassium cells of approximately $7.6 \mathrm{~cm}$. diameter and aperture, as figured in Type B by Campbell and Ritchie (1929).

The deck cell is contained in a light metal case, arranged for gimbal mounting, the gimbal ring remaining in a housing upon the deck, while the metal cell case can be removed to safety when not in use.

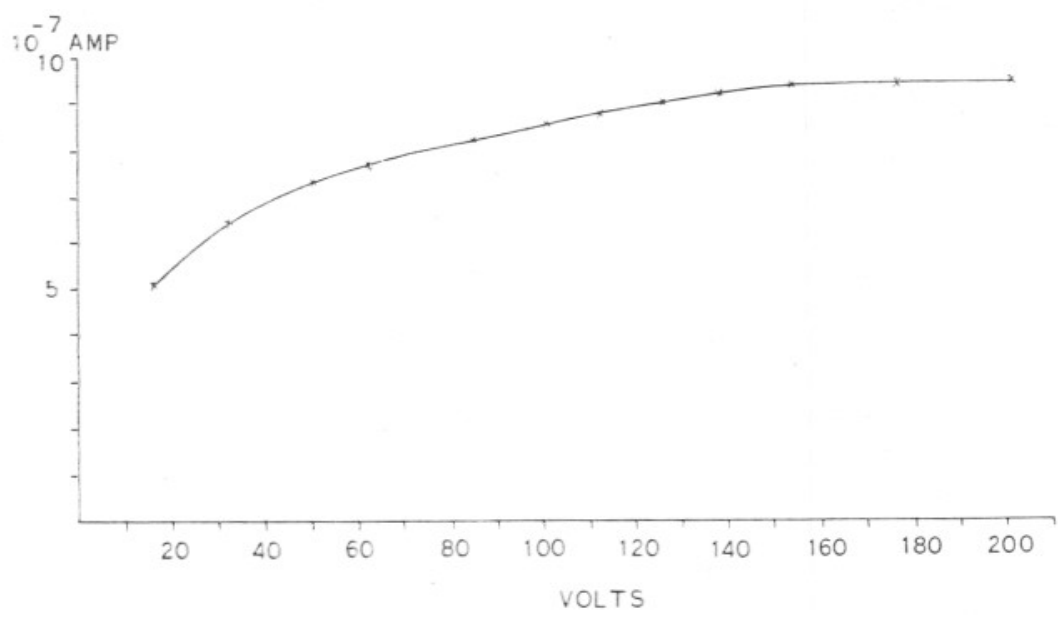

Fig. 2.

Over the window of the photo-electric cells discs of double surface flashed opalised glass are placed. These are held in position by three screw clips. It was found that owing to the great sensitivity of the cells, it is necessary at times to make use of diaphragms. These are of brass, $0.8 \mathrm{~mm}$. thick, with central apertures 3.8 and $0.6 \mathrm{~cm}$. in diameter. Figure 2 shows the voltage sensitivity curve for the vacuum cell housed in submarine photometer No. 1. From this it may be seen that at 140 to 150 volts saturation has been obtained. It is, however, quite permissible to operate the cell at 60 volts, at which point the sensitivity change amounts only to 0.33 per cent per volt. It seems safe to assume that the voltage sensitivity coefficient for the similar vacuum cell housed in the deck photometer is approximately the same.

Figure 3 shows the voltage sensitivity curve for the gas-filled cell housed in submarine photometer No. 2. The curve on the right was obtained with the large aperture diaphragm in position. The curve on the left was obtained subsequently without diaphragm. The point 
marked $\mathrm{F}$ shows the reading obtained with the diaphragm in position at 16 volts after the first curve had been obtained. The sensitivity has much increased since the cell had been raised to a high voltage. For this reason in practice measurements are made after the cell has been caused to glow, by momentarily connecting it with a high voltage. In this cell the necessary voltage is 201 in the absence of light. It is inadvisable to work

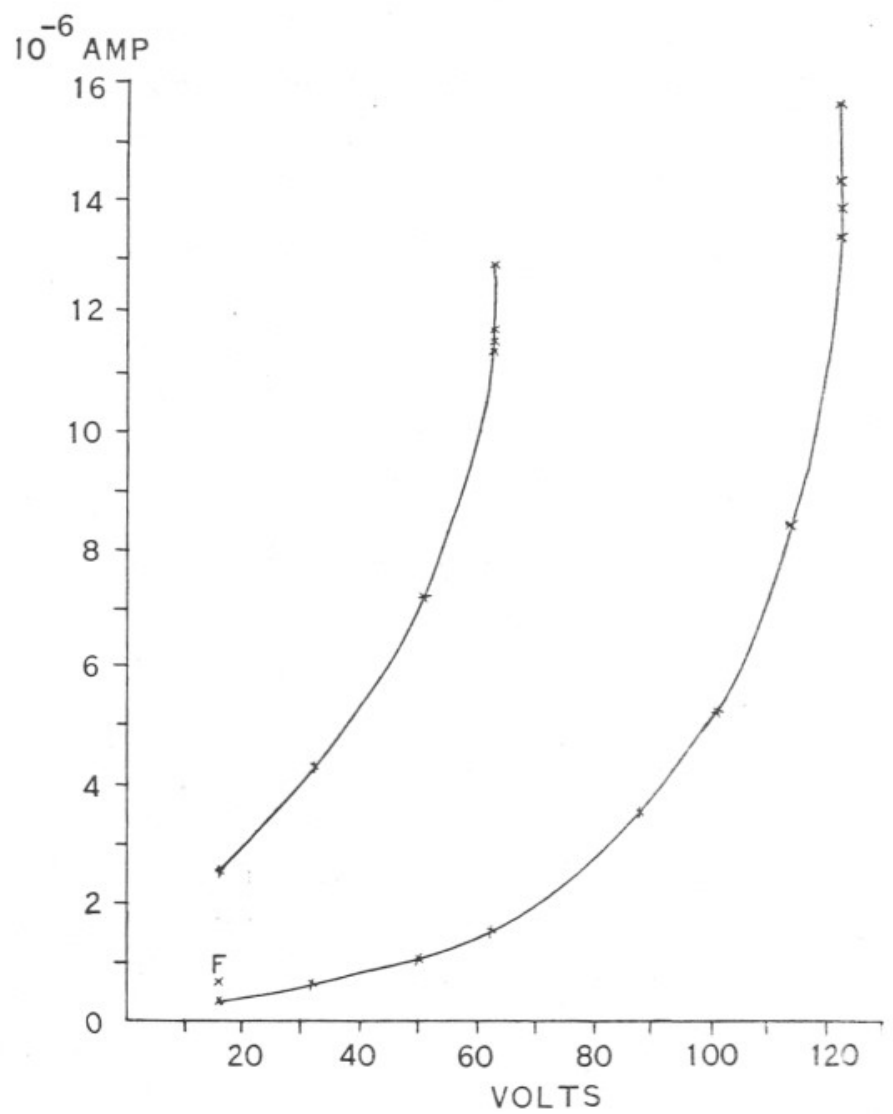

FIG. 3 .

this cell under conditions leading to the production of a current greater than $50 \mu \alpha$ (micro-amperes) owing to the steep rise in the curve at this reading. The deck photometer was standardised in diffused daylight against a similar vacuum potassium cell, which had been standardised by Poole and Atkins against an open carbon arc lamp (1928). This photometer had been in use for several years and was tested with a special lamp from time to time. It was shown that it had changed only slightly, if at all. The sensitivity is such that a current of $10^{-9}$ ampere is produced by a 
vertical illumination of 40 metre candles or $42 \cdot 4$ for uniformly diffused light. When compared in diffused daylight, the new deck photometer was found to be 109 times as sensitive as the standard. Accordingly the Atlantis photometer at 60 volts anode potential gives one micro-ampere for 370 m.c. vertical illumination, or with uniformly diffused light for an illumination of 390 metre candles. The diaphragm reduces the illumination approximately to one-sixth, actually it is reduced 5.95 times. Consequently with diaphragm in position the vertical illumination necessary to produce one micro-ampere is 2200 metre candles vertical illumination or 2320 m.c. for diffuse light.

The No. 1 vacuum sea photometer at 60 volts anode potential requires 870 metre candles to produce one $\mu \alpha$, or with uniformly diffused light 920 m.c. With diaphragm in position the values are respectively 5300 and 5600 metre candles. The gas-filled cell must not be regarded as quite constant in its behaviour, but the values given are those obtained immediately after the instantaneous glow when it is in its most constant and highly sensitive condition, according to the Research Staff of the General Electric Company (see also Atkins, 1931). With diaphragm in position and at 63 volts anode potential the gas-filled cell requires 1380 metre candles to give one $\mu \alpha$, or 900 m.c. vertical illumination at 85 volts.

Without diaphragm at 63 volts 232 metre candles produce one $\mu \alpha$, and at 85 volts 151 metre candles give one $\mu \alpha$. It may be seen therefore that under these conditions the cell will measure down to less than onesixth of a metre candle. For low illuminations the voltage may be increased very considerably and still smaller illuminations can then be measured.

\section{The Neon Discharge Tube Photometer.}

In addition to the potentiometer for measuring the photo-electric currents, one of Dr. J. H. J. Poole's neon lamp devices was provided. This is an extremely convenient means of measuring photo-electric currents, by counting the flashes of the neon lamp, the speed of which depends upon the amount of current flowing into a condenser, and therefore upon the rate at which the condenser builds up to sufficient voltage to discharge through the neon lamp. This instrument is illustrated in Figure 4. Its extreme simplicity is very attractive, and its application may be extended much beyond the present purpose. One feature worthy of note is that a given number of flashes can be regarded as proportional to a definite quantity of light, irrespective of the time taken. Thus the photographer can calibrate any emulsion in terms of the number of flashes necessary to give correct exposure, irrespective of the intensity of illumination.

The neon discharge tube photometer was assembled exactly as figured 
by J. H. J. and H. H. Poole (1930), with the exception that the paraffin wax was extended to cover all the internal wiring in the housing instead of being placed around the neon discharge tube only. The petticoat type of terminal was used on the outer side of the casing, as shown in Figure 4.

The apparatus contains four condensers of capacity 0.5 to $0.0005 \mu \mathrm{F}$. Even with $0.5 \mu \mathrm{F}$. the current given by the highly sensitive photoelectric cells supplied with this outfit was so great that the flashing in bright daylight was too rapid to count, even with the diaphragm necessary for use with the potentiometer apparatus. Accordingly a smaller

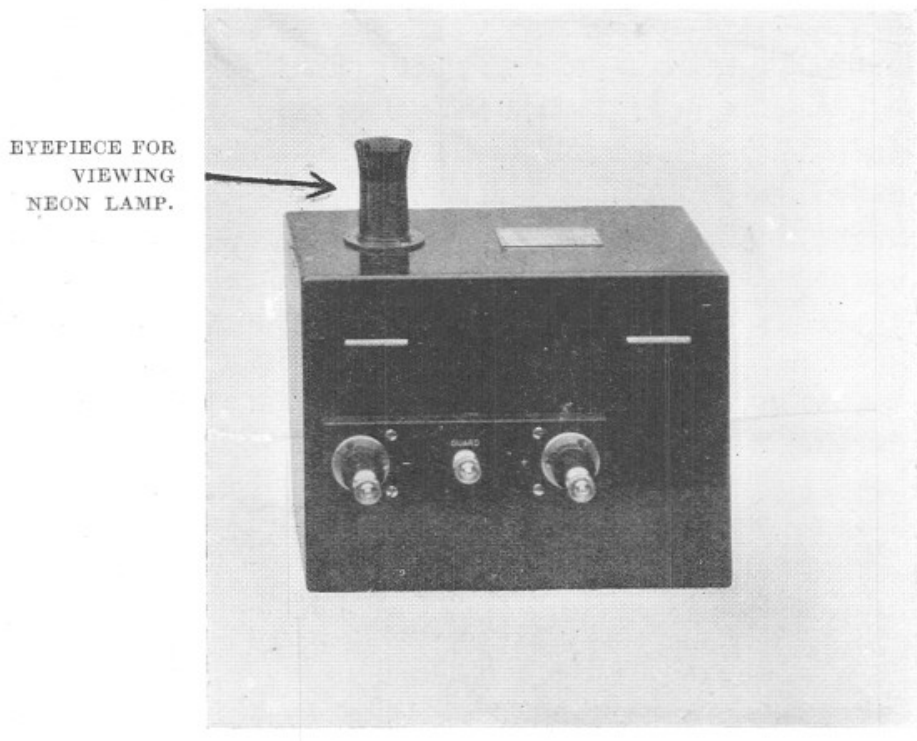

FIG. 4.

diaphragm, $0.6 \mathrm{~cm}$. aperture, was obtained for use with the neon discharge tube.

The time before the ship sailed was too short to permit of a complete standardisation of the sensitivity of the neon discharge tube photometer with the various condensers. It was, however, ascertained that when one of the photo-electric cells was almost closed and placed in diffused light in a room so that it gave a current of $30 \times 10^{-9}$ ampere, the neon lamp just maintained a slow rate of flash. Its sensitivity, therefore, appears to be ample for use down to a considerable depth, though its sphere of usefulness is most pronounced in that region, immediately under the surface and at small depths, at which the light varies very rapidly owing to the motion of the waves.

The high-tension batteries for use with the neon discharge tube are 
housed in a suitable box with a small volt-meter attached to its lid. Flashing in the lamp began at a voltage of 236 and did not take place at lower voltages however great the illumination. For use it is advisable to have a voltage considerably - say, about 60 volts - above this, so that there may remain an adequate voltage for the working of the photoelectric cell at all times in the cycle of charge and discharge of the tube. The whole apparatus was taken on board the Atlantis and a trial was made at sea in the neighbourhood of the Eddystone Lighthouse, off Plymouth. It was not possible to test the submarine photometers down to a depth of more than about 40 metres, but at such depth they showed no sign of leakage.

As regards the depth to which it is possible to measure illumination, it may be said the gas-filled cell is provided with cable to go to 200 metres. The illumination at that depth is probably quite measurable though small. Poole and Atkins (1929) arrived at an approximate formula connecting the depth at which it was possible to see the Secchi disc and the vertical absorbtion coefficient. The latter is roughly equal to 1.7 divided by the depth in metres. It is on record that in the open ocean the disc has been seen to as great a depth as 66 metres. From this a vertical absorbtion coefficient 0.026 is derived; such a value would lead one to expect a quite measurable amount of light at 200 metres. The results obtained on board the Atlantis are, however, to be awaited with great interest. They should offer an interesting comparison with visual observations made by Beebe in the bathysphere.

All the apparatus described in this paper was manufactured and assembled at the works of Messrs. H. Tinsley and Company, except the photo-electric cells and neon discharge tube, which were supplied by the General Electric Company, Wembley, Middlesex.

\section{REFERENCES.}

Atkins, W. R. G. 1931. Some experiments on the accuracy obtainable with gas-filled photo-electric cells. Sci. Proc. Roy. Dublin Soc., 20, $67-73$.

Campbell, N. R., and Ritchie, D. 1929. Photo-electric cells. London.

Poole, H. H. 1925. On the photo-electric measurement of submarine illumination. Loc. cit., 18, 99-115.

Poole, H. H., and Atrins, W. R. G. 1926. On the penetration of light into sea-water. J. Marine Biol. Assoc., 14, 177-198.

Poole, H. H., and Atkins, W. R. G. 1928. Further photo-electric measurements of the penetration of light into sea-water. Loc. cit., 15, $455-483$. 
Poole, H. H., and Atkins, W. R. G. 1929. Photo-electric measurements of submarine illumination throughout the year. Loc. cit., 16, $297-234$.

Poole, H. H., and Atkins, W. R. G. 1931. A preliminary comparison of the neon lamp and potentiometer methods of submarine photoelectric photometry. Loc. cit., 1\%, 617-631.

Poole, J. H. J. 1928. A simple form of photo-electric photometer, using a neon lamp to measure the current. Sci. Proc. Roy. Dublin Soc., 19, 17-25.

Poole, J. H. J., and Poole, H. H. 1930. The neon discharge tube photometer. In Photo-electric Cells and their Applications. Physical and Optical Societies Joint Discussion. June 4 and 5, 1930, 142-149.

Russell, F. S. 1925-1931. The vertical distribution of marine macroplankton, Pts. 1-10. J. Marine Biol. Assoc., 13-1\%.

Shelford, V., and GaIL, F. W. 1922. A study of light penetration into sea-water made with the Kunz photo-electric cell, with particular reference to the distribution of plants. Publ. Puget Sound Biol. Sta., 3, 141-176 